\title{
Comportamento de bovinos de corte em leillões
}

\section{Behavior of beef cattle at auctions}

\author{
Hemerson Cardoso de Sousa ${ }^{1}$; Mônica Maria de Almeida Brainer ${ }^{1 *}$; Heloísa Baleroni Rodrigues \\ de Godoy $^{1}$; Marcela Luzia Rodrigues Pereira ${ }^{2}$
}

\begin{abstract}
RESUMO
O objetivo deste trabalho foi avaliar características fenotípicas e parâmetros comportamentais de bovinos de corte em leilões realizados no município de Araguapaz/GO. Foram avaliados 33 lotes de bovinos de corte em um delineamento experimental inteiramente casualizado em leilão. Avaliou-se os efeitos do sexo, grupamento genético, categoria, quantidade de animais no lote, tempo de espera no curral e posição de redemoinhos de pelos faciais em relação à linha dos olhos sobre os parâmetros comportamentais. As médias dos parâmetros comportamentais foram analisadas através do Teste de Mann-Whitney a 10\% e Teste de Kruskal-Wallis a 5\%. Foi verificado que não houve diferença no padrão de comportamento dos bovinos dos diferentes sexos e faixas etárias em todas as variáveis estudadas. Entretanto, os animais dos grupamentos genéticos Gir, Nelore e Anelorado foram mais reativos à entrada da pista que os animais classificados como mestiços $(\mathrm{P}<0,05)$. A quantidade de animais no lote e o tempo de espera no curral influenciaram o comportamento dos animais durante a movimentação na pista de remate $(\mathrm{P}<0,05)$. A compreensão das características dos bovinos ajuda a entender o comportamento dos animais, facilitando, assim, a interação bovino e homem.
\end{abstract}

Palavras-chave: Bem-Estar; Bovinocultura; Pista de Remate; Temperamento.

\section{ABSTRACT}

The objective of this work was to evaluate phenotypic characteristics and behavioral parameters of beef cattle in auctions in the city of Araguapaz/GO. Thirty-three lots of beef cattle were evaluated in a completely randomized design at auction. The effects of sex, genetic grouping, category, number of animals in the flock, waiting time in the corral and position of facial hair swirls in relation to the eye line on behavioral parameters were evaluated. The means of behavioral parameters were analyzed using the MannWhitney test at $10 \%$ and the Kruskal-Wallis test at 5\%. It was verified that there was no difference in the behavior pattern of cattle of different sexes and age groups in all the variables studied. However, the animals of the genetic groups Gir, Nellore and Anelorado were more reactive to the entrance of the lane than the animals classified as crossbred $(\mathrm{P}<0.05)$. The number of animals in the lot and the waiting time in the corral influenced the behavior of the animals during the movement in the finishing lane $(\mathrm{P}<0.05)$. Understanding the characteristics of cattle helps to understand the behavior of animals, thus facilitating the interaction between cattle and humans.

Keywords: Welfare; Cattle breeding; Auction ring; Temperament

\footnotetext{
${ }^{1}$ Instituto Federal Goiano Campus Ceres.

${ }^{2}$ UniGoiás.

*E-mail: monica.brainer@ifgoiano.edu.br
} 


\section{INTRODUÇÃO}

Em 2020, o rebanho bovino nacional cresceu 1,5\%, chegando a 218,2 milhões de cabeças, maior efetivo desde 2016. O Centro-Oeste respondeu por $34,6 \%$ do total (75,4 milhões), sendo que, Mato Grosso e Goiás mantiveram-se com os maiores rebanhos bovinos do país e, juntos, foram responsáveis por 25,8\% do efetivo nacional (IBGE, 2021). Entretanto, a viabilidade financeira da criação de bovinos pode apresentar resultados variáveis em função dos custos com a alimentação e preços de aquisição e venda dos animais (NEIVA JÚNIOR et al., 2020).

De acordo com Valle et al. (2007), o mercado consumidor prioriza sistemas de produção que respeitem o bem estar animal, do nascimento ao abate. O conhecimento e o respeito à biologia dos animais de produção, além de permitir a melhoria de seu bem-estar, proporciona também melhores resultados econômicos com o aumento da produtividade e da qualidade do produto final. Diversos estudos já demonstraram que o manejo pré-abate influencia significativamente a qualidade da carne, do couro, bem como, o aproveitamento da carcaça.

O sistema de comercialização de animais em leilões vem cada vez sendo mais concretizado no país. Este sistema consiste em reunir os animais em um ambiente, onde todos os produtores têm acesso com boa visualização, desde o curral de espera até a pista de remate, em que a venda é intermediada por um leiloeiro, e os interessados ofertam valores (lances crescentes), sendo que o vendedor tem direito de aceitar ou recusar a oferta (MACHADO FILHO, 1994). O mercado comercial de venda de animas em leilão movimenta a economia dos municípios, incentivando assim, os produtores a comercializar seus animais.

De acordo com Borba (2004), o desempenho dos bovinos nos recintos de leilões pode representar a valorização ou não da comercialização do animal, pois é necessário que apresentem a postura de quando estão em liberdade para serem apresentados como produtos diferenciados.

A avaliação do temperamento de bovinos é uma ferramenta utilizada pela pesquisa para o aperfeiçoamento dos sistemas de criação e que tem consequências práticas e econômicas, portanto merece atenção dos produtores rurais (SILVEIRA et al, 2008).

Tendo em vista a relevância do temperamento na produção animal, têm aumentado os estudos relacionados ao comportamento animal, com o objetivo de compreender as relações do bem-estar com o sistema de produção. Estresse é o principal indicador para avaliar o bem-estar animal (MARCHI, 2012).

Grandin et al (1995) verificaram que a localização do redemoinho de pelos faciais no gado bovino pode ser um instrumento de avaliação do comportamento desses animais. Resultados de várias pesquisas desses autores revelaram forte correlação entre a localização dos redemoinhos e a reação dos bovinos, sendo que os animais que apresentam o redemoinho mais alto na face parecem estar mais propensos a entrar em pânico durante a contenção em comparação aos animais com redemoinhos mais baixos (LANIER et al., 2001). 
Rotinas e procedimentos inadequados nas fazendas, transporte e leilões ou exposição de animais aumentam a frequência de contusões na carcaça e de cortes escuros na carne, resultando em prejuízos financeiros para o produtor. Além disso, a ação direta do homem, ao agredir ou acuar os animais e a formação de novos lotes, desrespeitando seus padrões de organização social, contribuem para o aumento das interações agressivas entre os animais (VALLE et al., 2007).

O objetivo deste trabalho foi avaliar o comportamento de bovinos de corte de diferentes categorias em leilões na cidade de Araguapaz/GO.

Os artigos devem conter no máximo 15 páginas ao todo em folha tamanho A4. As margens laterais devem estar em $3 \mathrm{~cm}$ e as margens superior e inferior, $2,5 \mathrm{~cm}$.

\section{METODOLOGIA}

A pesquisa foi realizada durante os leilões de bovinos de corte dos dias 21 de abril e 21 de maio de 2016 nas dependências do Leilão do Pecuarista, localizado na Fazenda Santa Bárbara, zona rural do município de Araguapaz/GO, situada no Vale do Araguaia, com as seguintes coordenadas geográficas: latitude $15^{\circ} 05^{\prime} 27^{\prime \prime} \mathrm{S}$, longitude $50^{\circ} 37^{\prime} 56^{\prime \prime} \mathrm{W}$ e altitude de 304 metros. Foram realizadas avaliações de características fenotípicas e parâmetros comportamentais dos animais na entrada, durante a movimentação e na saída da pista de remate dos leilões sob condições de estresse durante o manejo.

De acordo com a rotina do evento, após a chegada os animais eram desembarcados e encaminhados ao curral de apartação, onde havia a separação em lotes e marcação com a numeração correspondente ao lote na região dorso-lombar do lado esquerdo dos bovinos. Os animais eram originários de diferentes propriedades com situações distintas de manejo e alimentação.

Após a divisão dos lotes, os animais eram encaminhados para os currais de espera a céu aberto de acordo com o cronograma de execução do leilão. Os animais permaneceram nos currais de espera por um período que variou de duas a seis horas, com temperatura ambiente em torno de $32^{\circ}$ graus.

A condução dos animais dos currais de espera para a pista de remate era realizada por funcionários utilizando ferrões e bandeira. A abertura da porteira de entrada, condução da movimentação dos animais no interior da pista e fechamento da porteira de saída era efetuada por um funcionário a pé. Cada lote permaneceu na pista de remate de um a quatro minutos.

A pista de remate situa-se em local coberto, com piso de areia, em formato de um semicírculo com uma área de $40 \mathrm{~m}^{2}$ cercada com cabos de aço até uma altura de dois metros e contendo um poste de sustentação ao centro da pista.

Como os lotes eram formados com diferentes quantidades de animais, foi realizada a identificação de dois animais por lote de forma aleatória para a avaliação dos parâmetros comportamentais e fenotípicos. Foi realizada uma marcação de cor azul ou vermelha em ambos 
os lados do cupim de cada animal para facilitar a visualização durante a movimentação na pista de remate.

Os parâmetros comportamentais em relação ao ambiente, sons e movimento do leiloeiro e público foram avaliados na entrada, permanência e saída dos animais da pista de remate. Os avaliadores foram distribuídos da seguinte forma: um avaliador situou-se na parte exterior do recinto, onde obteve melhor visão dos lotes ao entrar e o outro avaliador na parte superior da pista de remate junto ao leiloeiro (avaliação da permanência e saída dos animais da pista). As avaliações comportamentais foram realizadas com o auxílio de filmadoras e formulários para facilitar a análise e classificação dos comportamentos em escores.

Foram avaliados 33 lotes de bovinos em um delineamento experimental inteiramente casualizado, sendo que cada dupla de bovinos marcados no lote constituiu uma unidade experimental. Foram avaliados os efeitos do sexo (machos e fêmeas), grupamento genético (Nelores, Anelorados, Mestiços e Gir), faixa etária ( 0 a 12 meses, 13 a 24 meses, acima de 25 meses), quantidade de animais no lote ( 1 a 3, 4 a 10 e acima de 11 animais), tempo de espera no curral ( $2 \mathrm{~h}$ a $3 \mathrm{~h} 45 \mathrm{~min}$; $3 \mathrm{~h} 50 \mathrm{~min}$ a $5 \mathrm{~h}$ e $5 \mathrm{~h}$ a $6 \mathrm{~h} 30 \mathrm{~min})$ e posição de redemoinhos de pelos faciais (abaixo; mesmo nível; acima e bem acima da linha dos olhos) sobre as variáveis de parâmetros comportamentais. Foram considerados mestiços os animais que possuíam sangue de raças europeias.

A posição do redemoinho de pelos faciais (RED) foi avaliada através da observação de sua localização na face do animal em relação à linha média dos olhos. Os animais foram observados durante a marcação na passagem pelo tronco. Foram utilizados os escores de posição do redemoinho em relação à linha dos olhos, sendo: 1 - abaixo; 2 - mesmo nível; 3 - acima e 4 - bem acima.

Os parâmetros comportamentais foram avaliados de acordo com escores adaptados de Silveira et al. (2006), sendo eles:

a) Escore de Entrada na Pista (EEP), definido pela reatividade de entrada na pista com os seguintes escores: $1=$ sem ajuda (animal entra normalmente), $2=$ com ajuda (animal que será ajudado de alguma forma, com a utilização de bandeiras e ferrão), 3= com resistência (animal quando se depara com entrada na pista não sai do lugar);

b) Escore de Movimentação na Pista (EMP), definido pelo comportamento do animal na pista de remate considerando os seguintes escores: 1= caminha quieto (animal agindo com naturalidade), $2=$ trota continuamente ou caminha, $3=$ mais veloz que o trote, $4=$ golpe de cabeça (animal defere golpes de cabeça em outros animais);

c) Saída da Pista (SP), definido pela reatividade dos animais durante a saída, considerando os seguintes escores: $1=$ calmo (saída normalmente), 2=agitado (animal saindo assustado), $3=$ com ajuda. 
d) Vocalização (VOC), definido pelo mugido do animal durante a entrada, permanência e/ou saída da pista considerando os seguintes escores: 1= não (considerando apenas ausência), $2=\operatorname{sim}$ (independente da frequência).

e) Coices (COI), definido por coices efetuados pelo animal, considerando seguintes escores: $1=$ não (considerando apenas ausência), $2=\operatorname{sim}$ (independente da frequência, local e altura dos coices).

As análises estatísticas foram realizadas utilizando o programa Assistat 7.7 (Silva, 2016), sendo as médias dos parâmetros comportamentais relacionadas ao sexo e localização do redemoinho avaliadas através do Teste de Mann-Whitney a $10 \%$ e as médias relacionadas à quantidade de animais no lote, faixa etária, grupamento genético e tempo de espera no curral avaliadas através do Teste de Kruskal-Wallis a 5\%.

\section{RESULTADOS E DISCUSSÃO}

Foram avaliados lotes compostos por bovinos machos e fêmeas de diferentes idades. Do total de 33 lotes avaliados, $54,5 \%$ eram de machos e $45 \%$ de fêmeas, enquanto que $66,7 \%$ estavam na faixa etária de zero a 12 meses, $24,2 \%$ de 13 a 24 meses, $6,1 \%$ acima de 25 meses e 3\% acima de 36 meses.

Através das análises das médias dos escores comportamentais de acordo com os diferentes sexos $(\mathrm{P}<0,10)$ e faixas etárias $(\mathrm{P}<0,05)$, foi verificado que não houve diferença no padrão de comportamento dos bovinos em todas as variáveis estudadas (EEP, EMP, SP, COI e VOC), conforme pode ser observado na Tabela 1.

Tabela 1. Médias dos escores de comportamento de bovinos de corte na entrada, permanência e saída da pista de remate, vocalização e coices em leilões em Araguapaz/GO de acordo com o sexo e faixa etária.

\begin{tabular}{lccccc}
\hline Parâmetros & \multicolumn{5}{c}{ Variáveis analisadas } \\
\hline Sexo $^{1}$ & $\begin{array}{c}\text { Entrada na } \\
\text { pista* }^{*}\end{array}$ & $\begin{array}{c}\text { Movimento } \\
\text { na pista }\end{array}$ & $\begin{array}{c}\text { Saída da } \\
\text { pista }^{*}\end{array}$ & Vocalização $^{\#}$ & Coices $^{\circledR}$ \\
\hline Macho & 1,24 & 2,29 & 1,41 & 1,05 & 1,11 \\
Fêmeas & 1,6 & 2,47 & 1,5 & 1,03 & 1 \\
\hline $\mathrm{P}$ & P>0,10 & P>0,10 & P>0,10 & P>0,10 & P>0,10 \\
\hline Faixa Etária & Entrada na & Movimento & Saída da & Vocalização & Coices \\
& pista & na pista & pista & & \\
\hline 0 a 12 meses & 1,32 & 2,38 & 1,47 & 1,06 & 1,06 \\
13 a 24 meses & 1,38 & 2 & 1,38 & 1 & 1,08 \\
\hline
\end{tabular}




\begin{tabular}{llllll}
\hline $\mathrm{P}$ & $\mathrm{P}>0,05$ & $\mathrm{P}>0,05$ & $\mathrm{P}>0,05$ & $\mathrm{P}>0,05$ & $\mathrm{P}>0,05$
\end{tabular}

${ }^{1}$ Teste de Mann-Whitney a $10 \% ;{ }^{2}$ Teste de Kruskal-Wallis a 5\%

${ }^{*}$ Escores: 1 = sem ajuda; 2 = com ajuda; 3 = com resistência.

** Escores: 1 = caminha quieto; 2 = trota continuamente ou caminha; $3=$ mais veloz que o trote, $4=$ golpe de cabeça

\# Escores: 1 = calmo; 2 = agitado; 3 = com ajuda.

\#\# Escores: 1 = não; 2 = sim.

${ }^{\circledR}$ Escores: 1 = não; 2 = sim.

Entretanto, alguns trabalhos apresentaram resultados que comprovam diferenças nos comportamentos de machos e fêmeas, assim como, em animais de diferentes idades. Silveira (2005), verificou que os machos apresentaram menor reatividade quando comparados às fêmeas para os escores de entrada e movimentação em pista. Do mesmo modo, Argolo et al (2010) em uma revisão de comportamento e temperamento em ruminantes, descrevem que o temperamento do macho é mais estável do que o das fêmeas, pois estas sofrem alterações hormonais.

Aguilar (2007) verificou que as fêmeas jovens (bezerras) apresentaram uma disposição a serem ativas e as adultas a serem calmas, sendo que os machos jovens (bezerros) exibiram uma tendência a serem perturbados e os adultos a serem inquietos. De acordo com o autor, os animais jovens apresentam uma disposição a serem mais reativos, provavelmente devido à falta de experiência prévia a determinados manejos.

Ludke et al. (2012) ressaltam que bovinos que tiveram pouco contato com humanos nas propriedades ou que foram submetidos a um manejo agressivo apresentam reações de medo intenso, o que pode dificultar o manejo nos leilões. Dessa forma, deve-se incentivar a mudança das práticas de manejo nas propriedades, com mais interações positivas entre manejadores e bovinos, o que proporcionará melhor qualidade de vida na criação.

Quanto ao grupamento genético, bovinos da raça Nelore e mestiços corresponderam a $36 \%$ e $30 \%$ dos lotes, respectivamente, sendo que animais anelorados e da raça Gir foram $21 \%$ e $13 \%$ dos lotes, respectivamente.

Através das análises das médias dos escores comportamentais de acordo com os diferentes genótipos foi constatado que os animais dos grupamentos genéticos Gir, Nelore e Anelorado foram mais reativos à entrada da pista que os animais classificados como mestiços $(\mathrm{P}<0,05)$. Dos três grupos raciais mais reativos, os bovinos da raça Gir apresentaram uma maior resistência na entrada da pista de remate, tendo que serem guiados ou estimulados de alguma forma, com a utilização de bandeiras e ferrão. Entretanto, não houve diferença no comportamento dos diferentes grupos raciais durante a permanência e saída da pista de remate, e nem com relação à vocalização e coices (Tabela 2). 
Tabela 2. Médias dos escores de comportamento de bovinos de corte na entrada, permanência e saída da pista de remate, vocalização e coices em leilões em Araguapaz/GO de acordo com o grupamento genético e localização do redemoinho.

\begin{tabular}{|c|c|c|c|c|c|}
\hline \multirow{2}{*}{$\begin{array}{l}\text { Parâmetros } \\
\text { Grupamento } \\
\text { Genético }^{1}\end{array}$} & \multicolumn{5}{|c|}{ Variáveis analisadas } \\
\hline & $\begin{array}{c}\text { Entrada na } \\
\text { pista* }\end{array}$ & $\begin{array}{l}\text { Movimento } \\
\text { na pista** }\end{array}$ & $\begin{array}{l}\text { Saída da } \\
\text { pista }^{\#}\end{array}$ & Vocalização"\#\# & Coices $^{@}$ \\
\hline Nelore & $1,6 \mathrm{ab}$ & 2,4 & 1,4 & 1 & 1,05 \\
\hline Mestiço & $1,15 \mathrm{a}$ & 2,25 & 1,3 & 1 & 1,1 \\
\hline Anelorado & $1,21 \mathrm{ab}$ & 2,28 & 1,5 & 1,21 & 1,07 \\
\hline Gir & $2 \mathrm{~b}$ & 2,62 & 2 & 1 & 1 \\
\hline $\mathrm{P}$ & $\mathrm{P}<0,05$ & $\mathrm{P}>0,05$ & $\mathrm{P}>0,05$ & $\mathrm{P}>0,05$ & $\mathrm{P}>0,05$ \\
\hline $\begin{array}{ll}\text { Localização } & \text { do } \\
\text { redemoinho }^{2} & \end{array}$ & $\begin{array}{c}\text { Entrada na } \\
\text { pista }\end{array}$ & $\begin{array}{l}\text { Movimento } \\
\text { na pista }\end{array}$ & $\begin{array}{l}\text { Saída da } \\
\text { pista }\end{array}$ & Vocalização & Coices \\
\hline $\begin{array}{l}\text { Acima à linha } \\
\text { dos olhos }\end{array}$ & $1,23 \mathrm{a}$ & 2,12 & 1,38 & 1,00 & 1,08 \\
\hline $\begin{array}{l}\text { Bem acima à } \\
\text { linha dos olhos }\end{array}$ & $1,5 \mathrm{~b}$ & 2,23 & 1,43 & 1,07 & 1,03 \\
\hline $\mathrm{P}$ & $\mathrm{P}<0,10$ & $\mathrm{P}>0,10$ & $\mathrm{P}>0,10$ & $\mathrm{P}>0,10$ & $\mathrm{P}>0,10$ \\
\hline $\begin{array}{l}\text { 'Testes de Kruskal- } \\
\text { "Escores: } 1 \text { = sem aju } \\
\text { Escores: } 1 \text { = camin } \\
\text { de cabeça } \\
{ }^{4} \text { Escores: } 1 \text { = calmo; } \\
{ }^{4 \#} \text { Escores: } 1 \text { = não; } 2 \\
{ }^{0} \text { Escores: } 1 \text { = não; } 2 \\
\text { do Teste de Mann-W1 }\end{array}$ & $\begin{array}{l}\text { lis a } 5 \% ;{ }^{2} \mathrm{~T} \\
\text { a } 2=\text { com a } \\
\text { quieto; } 2= \\
=\text { agitado; } 3 \\
\text { sim. } \\
\text { sim. a,b }=1 \\
\text { ney a } 10 \% .\end{array}$ & $\begin{array}{l}\text { de Mann-Wh } \\
\text { a; } 3=\text { com res } \\
\text { a continuamer } \\
\text { com ajuda. } \\
\text { lias seguidas } p\end{array}$ & $\begin{array}{l}\text { y a } 10 \% \\
\text { cia. } \\
\text { ou caminh } \\
\text { etras distin }\end{array}$ & $\begin{array}{l}=\text { mais veloz qu } \\
\text { as colunas dife }\end{array}$ & te, $4=$ golp \\
\hline
\end{tabular}

Resultados semelhantes foram encontrados no trabalho de Silveira et al. (2008), que demonstram que os animais da espécie Bos indicus e os cruzados apresentam maior reatividade em relação aos europeus, caracterizando-os como animais mais nervosos ou mais agitados.

Silveira et al. (2006) observaram em seu trabalho que os animais cruzados com predominância de sangue zebuíno apresentaram maiores escores para todas as variáveis estudadas em relação aos demais, demonstrando maior reatividade. Diferenças genéticas podem afetar as reações de estresse durante o manejo, de forma que os animais que possuem genética excitável são mais propensos a se agitar quando confrontados a uma nova situação (Silveira et al., 2010).

Entretanto, Ludtke et al (2012) afirmam que rebanhos de algumas fazendas podem ser mais difíceis de manejar do que de outras, devido ao modo como os animais são tratados na criação. Por isso, em leilões, bovinos de uma mesma raça podem ser mais difíceis de manejar que outros. 
Quanto ao parâmetro de localização do redemoinho em relação à linha dos olhos, foi verificado que todos os animais avaliados nos leilões apresentavam redemoinhos faciais acima e bem acima à linha dos olhos, que representam os animais de comportamento mais reativo. À entrada da pista, os animais com redemoinho bem acima dos olhos foram mais reativos que o outro grupo $(\mathrm{P}<0,10)$, entretanto para os demais parâmetros avaliados os dois grupos apresentaram médias semelhantes (Tabela 2).

Broucek et al. (2004) verificaram que as habilidades de aprendizagem e comportamento locomotor (velocidade) de novilhas leiteiras em ambiente desconhecido e confuso não foram influenciadas pela posição dos redemoinhos de pelos faciais. Os autores justificam que o fato de que os animais desse estudo terem sido submetidos a um manejo contínuo por tratadores e terem uma boa relação com humanos, os diferencia dos animais usados nos trabalhos da Dra. Grandin, que observou alta correlação entre a posição dos pelos faciais e o comportamento reativo dos animais. Observações casuais indicam que a relação entre a posição do redemoinho e o temperamento é mais facilmente observada em bovinos que não têm contato direto com pessoas (GRANDIN et al., 1995).

Do mesmo modo, neste estudo todos os animais avaliados eram procedentes de propriedades que adotavam manejo intensivo e, portanto os bovinos eram acostumados com o manejo e contato com humanos. Segundo Olmos e Turner (2008), a posição do redemoinho é um forte indicador de temperamento, porém parece ser limitado. Os pesquisadores ressaltaram que a medida se relaciona com alguns aspectos do temperamento, mas são necessários mais estudos para usá-la como ferramenta de seleção do temperamento em bovinos.

Durante as observações e apontamentos de campo ficou evidente que o comportamento dos animais variou de acordo com o tamanho dos lotes. Através das análises estatísticas foi possível comprovar que a porcentagem de animais reativos, ou seja, com maiores escores, diminuiu de acordo com o aumento de animais por lote durante a movimentação na pista de remate $(\mathrm{P}<0,05)$ (Tabela 3). Este comportamento, provavelmente, foi modulado pela experiência prévia do manejo, que se torna mais individual quando há menos animais no ambiente, causando um efeito maior do homem sobre o animal. Contudo, não foi observada nenhuma diferença no comportamento dos animais na entrada e saída da pista, assim como na vocalização e coices, independentemente da quantidade de animais no grupo.

Tabela 3. Efeito da quantidade de animais no lote e tempo de espera nos currais sobre o comportamento de bovinos de corte na entrada, movimento e saída da pista de remate e vocalização e coices em leilões de Araguapaz/GO.

Parâmetros Variáveis analisadas




\begin{tabular}{|c|c|c|c|c|c|}
\hline $\begin{array}{l}\text { Quantidade de } \\
\text { animais no lote }\end{array}$ & $\begin{array}{c}\text { Entrada na } \\
\text { pista* }\end{array}$ & $\begin{array}{l}\text { Movimento } \\
\text { na pista** }^{* *}\end{array}$ & $\begin{array}{l}\text { Saída da } \\
\text { pista }^{\#}\end{array}$ & Vocalizaçãó & Coices $^{\circledR}$ \\
\hline 1 a 3 & 1,67 & $3,07 \mathrm{~b}$ & 1,75 & 1,1 & 1,07 \\
\hline 4 a 10 & 1,20 & $2,00 \mathrm{a}$ & 1,25 & 1,00 & 1,05 \\
\hline Acima de 11 & 1,21 & $1,71 \mathrm{a}$ & 1,21 & 1,00 & 1,07 \\
\hline $\mathrm{P}$ & $\mathrm{P}>0,05$ & $\mathrm{P}<0,01$ & $\mathrm{P}>0,05$ & $\mathrm{P}>0,05$ & $\mathrm{P}>0,05$ \\
\hline $\begin{array}{l}\text { Tempo de espera } \\
\text { nos currais }\end{array}$ & $\begin{array}{c}\text { Entrada na } \\
\text { pista }\end{array}$ & $\begin{array}{c}\text { Movimento } \\
\text { na pista }\end{array}$ & $\begin{array}{c}\text { Saída da } \\
\text { pista }\end{array}$ & Vocalização & Coices \\
\hline $2 \mathrm{~h}$ a $3 \mathrm{~h} 45 \mathrm{~min}$ & 1,33 & $1,89 \mathrm{a}$ & 1,50 & 1,00 & 1,06 \\
\hline $3 \mathrm{~h} 50 \mathrm{~min}$ a $5 \mathrm{~h}$ & 1,38 & $2,13 \mathrm{ab}$ & 1,29 & 1,04 & 1,04 \\
\hline $5 \mathrm{~h}$ a $6 \mathrm{~h} 30 \mathrm{~min}$ & 1,47 & $2,82 \mathrm{~b}$ & 1,53 & 1,06 & 1,06 \\
\hline $\mathrm{P}$ & $\mathrm{P}>0,05$ & $\mathrm{P}<0,05$ & $\mathrm{P}>0,05$ & $\mathrm{P}>0,05$ & $\mathrm{P}>0,05$ \\
\hline
\end{tabular}

* Escores: 1 = sem ajuda; 2 = com ajuda; 3 = com resistência.

** Escores: 1 = caminha quieto; 2 = trota continuamente ou caminha; $3=$ mais veloz que o trote, $4=$ golpe de cabeça

\# Escores: 1 = calmo; 2 = agitado; 3 = com ajuda.

\#\# Escores: 1 = não; 2 = sim.

${ }^{@}$ Escores: 1 = não; 2 = sim.

$\mathrm{a}, \mathrm{b}=$ Médias seguidas por letras distintas nas colunas diferem entre si através do Teste de Kruskal-Wallis a $1 \%$ e $5 \%$.

A ansiedade e o medo, assim como o estresse, têm suas causas nas reações de defesa dos animais em resposta aos perigos encontrados ao novo ambiente. Ao se deparar com uma ameaça ao seu bem estar, à sua integridade física, ou até mesmo à sua sobrevivência, ele experimenta uma série de respostas comportamentais e neurovegetativas, que caracterizam a reação de medo (MARGIS et al, 2003).

De acordo com Eloy \& Pereira (2013) o isolamento de caprinos de seu grupo social pode aumentar o estresse emocional, refletindo em elevados níveis de cortisol, hormônio indicador de estresse. Em relação aos ataques durante a movimentação na pista, Margis et al. (2003) afirmaram que as respostas comportamentais básicas diante de um fator de estresse são o enfrentamento (ataque) ou fuga. Quando o sinal de perigo se torna explícito, os animais apresentam uma resposta imediata de enfrentamento ou fuga ao funcionário responsável pelo manejo na pista de remate.

Vidal (2010) relata que em recintos fechados os animais são muito sensíveis a ruídos intermitentes (apitos, microfonia aguda e alta), o que lhes deixam bastante nervosos e indóceis, dificultando a sua apresentação em pistas.

A fim de verificar se o tempo de espera no curral também teria influência no comportamento dos animais na pista de remate, os lotes foram divididos de acordo com faixas de tempo de espera ( $2 \mathrm{~h}$ a $3 \mathrm{~h} 45 \mathrm{~min}$, de $3 \mathrm{~h} 50 \mathrm{~min}$ a $5 \mathrm{~h}$ e de $5 \mathrm{~h}$ a $6 \mathrm{~h} 30 \mathrm{~min}$ ) e os escores de comportamento em cada faixa de tempo submetidos à análise estatística. 
De acordo com as análises estatísticas dos dados foi verificado que o tempo de espera no curral não influenciou o comportamento dos bovinos na entrada e saída da pista de remate, assim como, sobre a presença de vocalização e coices. Entretanto, foi verificado que durante a movimentação na pista os animais que permaneceram mais tempo no curral de espera apresentaram comportamento mais reativo que os que ficaram menos tempo esperando para entrar na pista $(\mathrm{P}<0,05)$, confirmando que o estresse do manejo e das condições no curral de espera influenciam o comportamento dos bovinos (Tabela 3).

O tempo em que os animais permanecem sem alimento e água reflete no seu bem-estar e no seu comportamento. Entretanto, é importante considerar que todos os animais utilizados neste estudo são provenientes de práticas de manejos de rotina, além de serem oriundos e adaptados à região do estudo que possui condições climáticas adversas (quente e seco). Provavelmente, por estarem acostumados a serem manejados nas condições climáticas do local, o tempo de espera nos currais não teve efeito sobre o comportamento na entrada e saída da pista de remate.

O sistema comercial de compra e venda da região entre os pecuaristas estimula o contato frequente e positivo entre seres humanos e animais, contribuindo para que a reatividade diminua a cada participação nas avaliações.

Gonsalves Neto et. al (2009), afirmam que a oportunidade de bezerros executarem comportamento social normal é influenciada pelas práticas de manejo e instalações. A prática comum de manejo de forma incorreta em fazendas comerciais influencia no desenvolvimento social deles mais tarde.

O criador, dentro das suas necessidades, pode estabelecer índices para estimar o temperamento dos animais aliando esta avaliação aos critérios de descarte. Identificando-se animais mais dóceis, a execução do manejo é facilitada, proporcionando não só um aumento do desempenho animal e na eficiência em relação ao serviço, mas também uma melhor interação homem/animal.

\section{CONCLUSÃO}

O grupamento racial, a localização do redemoinho facial, a quantidade de animais no lote e o tempo de permanência no curral de espera influenciam o comportamento de bovinos de corte em pista de remate de leilões. Animais com predominância de sangue zebuíno e redemoinho facial bem acima da linha dos olhos são mais reativos à entrada na pista e quanto menor o número de animais no lote e maior o tempo de espera, maior o comportamento reativo durante a movimentação na pista de remate de leilões.

A compreensão das características dos bovinos, tais como grupos raciais e comportamento gregário dos grupos, ajuda a entender os sentidos, sentimentos e comportamentos dos animais, facilitando, assim, a interação bovino e homem. 


\section{REFERÊNCIAS}

AGUILAR, N.M.A. Avaliação da reatividade de bovinos de corte e sua relação com caracteres reprodutivos e produtivos. 2007. 69 f. Dissertação (Mestrado em Zootecnia). Faculdade de Ciências Agrárias e Veterinárias, Universidade Estadual Paulista, Jaboticabal, SP, 2007. Disponível em: chromeextension://efaidnbmnnnibpcajpcglclefindmkaj/viewer.html?pdfurl=https $\% 3 \mathrm{~A} \% 2 \mathrm{~F} \% 2 \mathrm{~F}$ www.fcav.unesp.br\%2FHome\%2Fdownload\%2Fpgtrabs\%2Fzoo\%2Fm\%2F3029.pdf\& clen=391602\&chunk=true. Acesso em: 19 jan 2022.

ARGOLO L.S. et al. Comportamento e temperamento em ruminantes. Pubvet, Londrina, v.4, n.13, ed.118, art.795, 2010.

BORBA, E. Treinamento de bovinos para exposições e leilões. Rural Notícias, 31/08/2004. Disponível em: http://www.ruralnoticias.com.br/treinamento-de-bovinospara-exposicoes-e-leiloes/. Acesso em: 23 de maio de 2016.

BROUCEK, J. et al. Hair whorl position as a predictor of learning ability and locomoter behavior in cattle? Acta Veterinaria Brno, v.73, n.455-459, 2004. Disponível em: https://www.researchgate.net/publication/275807384_Hair_Whorl_Position_as_a_Predi ctor_of_Learning_Ability_and_Locomotor_Behavior_of_Cattle. Acesso em 19 jan 2022.

COSTA, M.J.R.P et al. Contribuição dos estudos de comportamento de bovinos para implementação de programas de qualidade de carne. In: ENCONTRO ANUAL DE ETOLOGIA, 2002, Natal. Palestras..., Natal: Sociedade Brasileira de Etologia, 2002. p. 71-89. Disponível em: chrome-

extension://efaidnbmnnnibpcajpcglclefindmkaj/viewer.html?pdfurl=http $\% 3 \mathrm{~A} \% 2 \mathrm{~F} \% 2 \mathrm{~F}$ www.grupoetco.org.br\%2Farquivos_br\%2Fpdf\%2Fcontriestcomp.pdf\&clen=227461\&c hunk=true. Acesso em: 19 jan 2022.

ELOY, A.M.X.; PEREIRA, E.P. Estresse na reprodução de caprinos machos. Revista Brasileira de Reprodução Animal, Belo Horizonte, v.37, n.2, p.156-163, 2013.

Disponível em: chromeextension://efaidnbmnnnibpcajpcglclefindmkaj/viewer.html?pdfurl=https $\% 3 \mathrm{~A} \% 2 \mathrm{~F} \% 2 \mathrm{~F}$ ainfo.cnptia.embrapa.br\%2Fdigital\%2Fbitstream\%2Fitem\%2F89243\%2F1\%2FAPIEstresse-na-reproducao.pdf\&clen=389285. Acesso em: 19 jan 2022.

GONSALVES NETO, J. et al. Comportamento social dos ruminantes. Revista Eletrônica Nutritime, v.6, ${ }^{\circ}$ 4, p1039-1055, 2009. Disponível em: chromeextension://efaidnbmnnnibpcajpcglclefindmkaj/viewer.html?pdfurl=https $\% 3 \mathrm{~A} \% 2 \mathrm{~F} \% 2 \mathrm{~F}$ www.nutritime.com.br\%2Farquivos_internos\%2Fartigos\%2F096V6N4P1039_1055JUL 2009_.pdf\&clen=640705\&chunk=true. Acesso em 19 jan 2022.

GRANDIN, T. et al. Cattle with whorl patterns above the eyes are more behaviorally agitated during restraint. Applied Animal Behaviour Science, v.46, p.117-123, 1995. Disponível em: https://doi.org/10.1016/0168-1591(95)00638-9. Acesso em: 19 jan 2022. 
IBGE - INSTITUTO BRASILEIRO DE GEOGRAFIA E ESTATÍSTICA. PPM 2020: rebanho bovino cresce $1,5 \%$ e chega a 218,2 milhões de cabeças. Agência IBGE Notícias, 29/09/2021. Disponível em: https://agenciadenoticias.ibge.gov.br/agenciasala-de-imprensa/2013-agencia-de-noticias/releases/31722-ppm-2020-rebanho-bovinocresce-1-5-e-chega-a-218-2-milhoes-de-cabecas. Acesso em: 19 jan. 2022.

LANIER, L.J. et al. A note on hair whorl position and cattle temperament in the auction ring. Applied Animal Behaviour Science, v.73, p.93-101, 2001. Disponível em: https://doi.org/10.1016/S0168-1591(01)00132-0. Acesso em: 19 jan 2022.

LUDTKE, C.B et al. Abate Humanitário de Bovinos. Rio de Janeiro: WSPA, 2012. 148p. Disponível em: chrome-

extension://efaidnbmnnnibpcajpcglclefindmkaj/viewer.html?pdfurl=https $\% 3 \mathrm{~A} \% 2 \mathrm{~F} \% 2 \mathrm{~F}$ www.gov.br\%2Fagricultura $\% 2$ Fpt-br $\% 2$ Fassuntos $\% 2$ Fproducao-animal $\% 2$ Farquivospublicacoes-bem-estar-animal\%2Fprograma-steps-2013-abate-humanitario-debovinos.pdf\&clen=6613241\&chunk=true. Acesso em: 19 jan. 2022.

MACHADO FILHO, A.P. Leilões de animais no Brasil. Revista de Administração, São Paulo, v.29, n.1, p.76-82, 1994.

MARCHI, P.G.F. Bem-estar animal e suas implicações na qualidade da carne bovina: diagnóstico da situação nos segmentos iniciais da cadeia produtiva no Estado de Mato Grosso. 2012. 88 f. Tese (Doutorado em Medicina Veterinária Preventiva). Faculdade de Ciências Agrárias e Veterinárias, Universidade Estadual Paulista, Jaboticabal, SP, 2012. Disponível em:

https://repositorio.unesp.br/handle/11449/103787. Acesso em: 19 jan. 2022.

MARGIS R. et al. Relação entre estressores, estresse e ansiedade. Revista de Psiquiatria do Rio Grande do Sul, v.25, supl.1, n. 65-74, 2003. Disponível em: https://doi.org/10.1590/S0101-81082003000400008. Acesso em: 19 jan. 2022.

NEIVA JÚNIOR, A.P.; FERREIRA, S.A.; PAULA, P.R.P.; TAVARES, V.B.; TEIXEIRA, R.M.A.; JAYME, C.G.; CAPPELLE, E.R. Viabilidade econômica do confinamento de novilhos Nelore e F1 (Angus x Nelore) com grão de milho inteiro na região de Lavras - MG. Brazilian Journal of Animal and Environmental Research, v.3, n.2, p.483-501, 2020. Disponível em: https://doi.org/10.34188/bjaerv3n2-008. Acesso em 19 jan. 2022.

OLIVEIRA, R. L. et al. Nutrição e manejo de bovinos de corte na fase de cria. Revista Brasileira de Saúde e Produção Animal, v.7, n.1, p. 57-86, 2006. Disponível em: https://www.researchgate.net/publication/281164205_Nutricao_e_manejo_de_bovinos_ de_corte_na_fase_de_cria. Acesso em: 19 jan. 2022.

OLMOS, G.; TURNER, S.P. The relationships between temperament during routine handling tasks, weight gain and facial hair whorl position in frequently handled beef cattle. Applied Animal Behaviour Science, v.115, p.25-36, 2008. Disponível em: http://dx.doi.org/10.1016/j.applanim.2008.05.001. Acesso em 19 jan. 2022.

SILVA, C. R. Parâmetros genéticos de escore de temperamento em bovinos da raça Nelore. 2013. 48 f. Dissertação (Mestrado em Genética e Melhoramento Animal). 
Faculdade de Ciências Agrárias e Veterinárias, Universidade Estadual Paulista, Jaboticabal, SP, 2013. Disponível em: chrome-

extension://efaidnbmnnnibpcajpcglclefindmkaj/viewer.html?pdfurl=https\%3A\%2F\%2F repositorio.unesp.br\%2Fbitstream\%2Fhandle\%2F11449\%2F92569\%2F000736054.pdf $\% 3$ Fsequence\%3D1\&clen=1405695. Acesso em: 19 jan 2022.

SILVA, N.T.A. et al. Etologia bovina. Cadernos Técnicos de Veterinária e Zootecnia, n.78, cap. 2, p.19-27, 2015.

SILVA, F.A.S. Assistat versão 7.7 pt - Assistência Estatística. Campina Grande: Universidade Federal de Campina Grande, 2016.

SILVEIRA, I.D.B. Influência da genética bovina na suscetibilidade ao estresse durante o manejo e seus efeitos na qualidade da carne. 2005. 180 f. Tese (Doutorado em Ciências). Faculdade de Agronomia Eliseu Maciel, Universidade Federal de Pelotas, Pelotas, RS, 2005. Disponível em: http://guaiaca.ufpel.edu.br/handle/123456789/2623. Acesso em: 19 jan. 2022.

SILVEIRA, I.D.B.; FISCHER, V.; MENDONÇA, G. Comportamento de bovino de corte em pista de remate. Ciência Rural, v.36, n.5, p. 1529-1533, 2006. Disponível em: https://doi.org/10.1590/S0103-84782006000500029. Acesso em: 19 jan. 2022.

SILVEIRA, I.D.B. et al. Relação entre os genótipos e temperamentos de novilhos Charolês X Nelore em confinamento. Revista Brasileira de Zootecnia, v.37, n.10, p.1808-1814, 2008. Disponível em: https://doi.org/10.1590/S151635982008001000014. Acesso em: 19 jan 2022.

SILVEIRA, I.D.B, FISCHER, V, MENDONÇA, G. Efeito do genótipo e da idade de ovinos na reatividade medida na pista de remate. Revista Brasileira de Zootecnia, v.39, n.10, p.2304-2309, 2010. Disponível em: https://doi.org/10.1590/S151635982010001000029. Acesso em: 19 jan. 2022.

VALLE, E.R. et al. Boas práticas agropecuárias - bovinos de corte. $1^{\text {a }}$ ed. Campo Grande/MS: Embrapa Gado de Corte, 2007. 86p. Disponível em: chromeextension://efaidnbmnnnibpcajpcglclefindmkaj/viewer.html?pdfurl=https $\% 3 \mathrm{~A} \% 2 \mathrm{~F} \% 2 \mathrm{~F}$ www.infoteca.cnptia.embrapa.br\%2Finfoteca $\% 2$ Fbitstream $\% 2 F d o c \% 2 F 40921 \% 2 \mathrm{~F} 1 \% 2$ FBPAJBSEMBRAPA.pdf\&clen=6763536. Acesso em: 19 já. 2022.

VIDAL, R.M. Princípios de comportamento animal (parte II). Web Artigos, 2010. Disponível em: <http://www.webartigos.com/artigos/principios-de-comportamentoanimal-parte-ii/33568. Acesso em: 24 de novembro de 2016. 